Provided for non-commercial research and education use. Not for reproduction, distribution or commercial use.

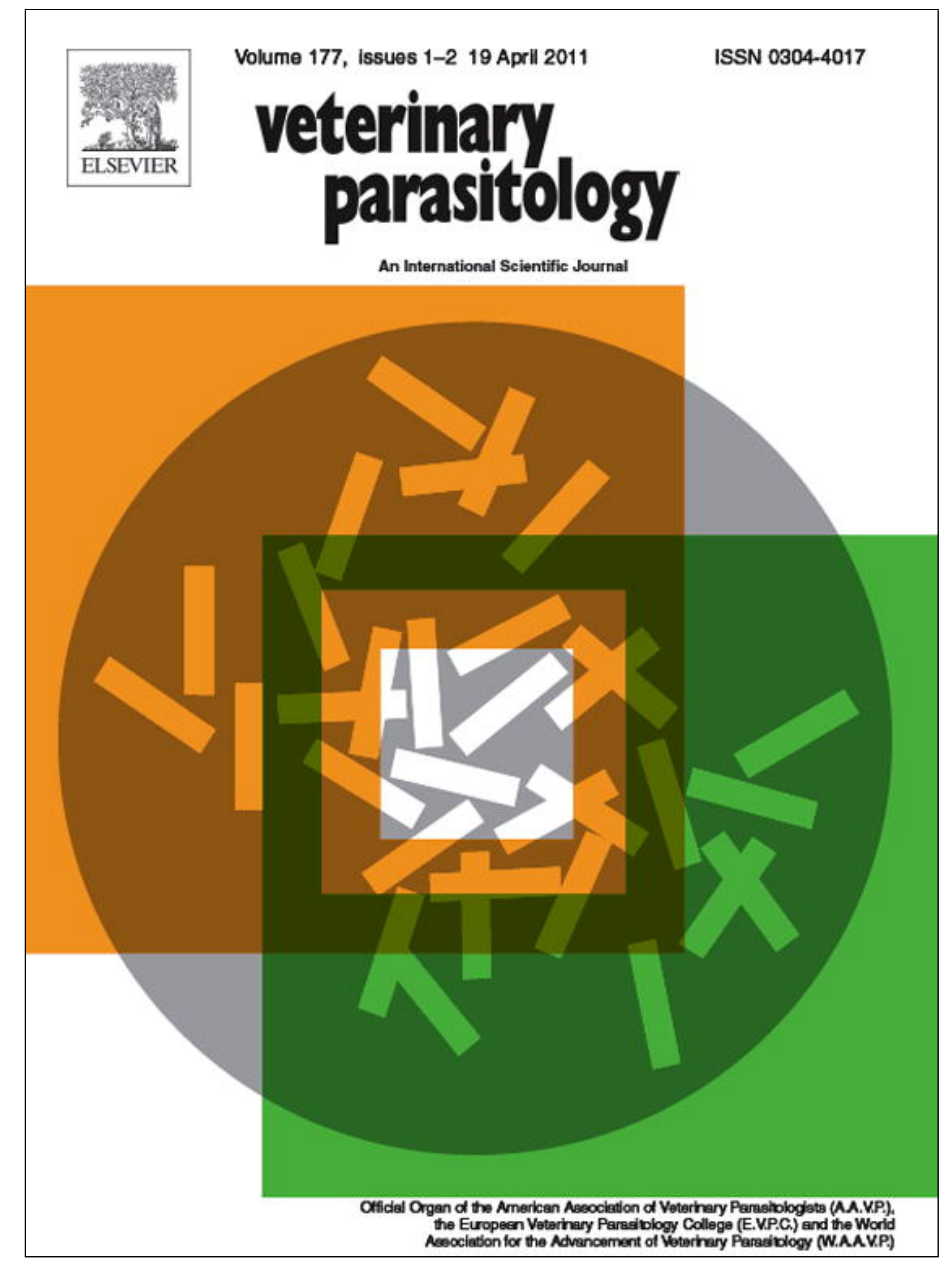

This article appeared in a journal published by Elsevier. The attached copy is furnished to the author for internal non-commercial research and education use, including for instruction at the authors institution and sharing with colleagues.

Other uses, including reproduction and distribution, or selling or licensing copies, or posting to personal, institutional or third party websites are prohibited.

In most cases authors are permitted to post their version of the article (e.g. in Word or Tex form) to their personal website or institutional repository. Authors requiring further information regarding Elsevier's archiving and manuscript policies are encouraged to visit:

http://www.elsevier.com/copyright 


\title{
Investigation on Opisthorchis felineus occurrence and life cycle in Italy
}

\author{
C. De Liberato ${ }^{a}, *, P$. Scaramozzino $^{\mathrm{a}}$, A. Brozzi $^{\mathrm{a}}$, R. Lorenzetti $^{\mathrm{a}}$, D. Di Cave $^{\mathrm{b}}$, E. Martini $^{\mathrm{c}}$,

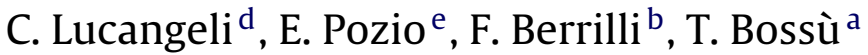 \\ a Istituto Zooprofilattico Sperimentale delle Regioni Lazio e Toscana, Via Appia Nuova 1411, 00178 Rome, Italy \\ b University of "Tor Vergata", Via Montpellier 1, 00133 Rome, Italy \\ c ASL VT2, Via Dante Alighieri 100, 01027 Montefiascone, Viterbo, Italy \\ d ASL RMF, via Dominici 3, 00062 Bracciano, Rome, Italy \\ e Istituto Superiore di Sanità, Viale Regina Elena 299, 00161 Rome, Italy
}

\section{A R T I C L E I N F O}

\section{Article history:}

Received 25 August 2010

Received in revised form

18 November 2010

Accepted 25 November 2010

\section{Keywords:}

Opisthorchis felineus

Opisthorchiasis

Tinca tinca

Zoonosis

Italy

\begin{abstract}
A B S T R A C T
Opisthorchiasis is a fish borne parasitic infection caused by helminths of the genus Opisthorchis (Digenea, Opisthorchiidae), affecting humans and other fish-eating mammals. Despite Opisthorchis felineus was first described in Italy in 1884, no cases of human opisthorchiasis were reported in this country until 2004; from then on, 4 outbreaks due to this species have been recorded in Central Italy. Following the more relevant of these outbreaks, involving 34 people in August 2007, snails, fishes and fecal samples collected from the Bolsena and Bracciano lakes (Central Italy) were analyzed in order to define the cycle of $O$. felineus in the area and investigate its prevalence in the different hosts. Pools of 20-40 snails each (4983 specimens altogether) of the genus Bithynia were analyzed by PCR for parasite DNA detection. Eight hundred and ninety-four fish belonging to 12 species were collected from the two lakes and tested for metacercariae both by muscle compression and digestion techniques. Eighty-seven fecal samples of 5 putative definitive host species were collected very close to the two lakes and tested for parasite eggs detection by formalin-ethyl acetate concentration technique. Identification at the species level of metacercariae and eggs, respectively, from fish and stool was confirmed by PCR analysis and sequencing. $O$. felineus DNA was detected in $0.08 \%$ (overall minimum infection rate) of snails of the genus Bithynia from the two lakes. The tench, Tinca tinca, was the only fish found infested in both lakes (prevalence 88.5\%). O. felineus eggs were found only in cat feces (prevalence $46.4 \%$ ). The tench represents the only threat for the human consumption in the study area while Coregonus sp., the most economically important species for the local fishery and frequently consumed raw marinated, resulted to be not infected. The high prevalence recorded both in fish and in definitive host suggests a widespread and massive presence of the parasite in the area. Further studies are needed to better investigate the possible role of some cyprinids species as intermediate hosts, in order to check their safety for human consumption.
\end{abstract}

(c) 2010 Elsevier B.V. All rights reserved.

\footnotetext{
* Corresponding author at: Istituto Zooprofilattico Sperimentale delle Regioni Lazio e Toscana, Parasitology and Veterinary Entomology Laboratory, Via Appia Nuova 1411, 00178 Rome, Italy.

Tel.: +39 0679099424; fax: +39 0679099331.

E-mail address: claudio.deliberato@izslt.it (C. De Liberato).
}

\section{Introduction}

Opisthorchiasis is a parasitic infection caused by helminths of the genus Opisthorchis (Digenea, Opisthorchiidae). Two species cause serious health problems in humans: Opisthorchis felineus in Asiatic countries of the former USSR and in Central-Eastern Europe and Opisthorchis viverrini in Southeast Asia. About 10 million people world- 
wide suffer from opisthorchiasis (WHO, 1995; Schuster, 2010) and their number is increasing in some areas (Keiser and Utzinger, 2005; Marcos et al., 2008). In particular, O. felineus affects 1.6 million people (Yossepowitch et al., 2004), causing abdominal pain, fever, diffuse myalgia, diarrhoea, cholangitis, pancreatitis and possibly, in long lasting chronic infections, cholangiocarcinoma (Sripa, 2003). Adult flukes, living in biliary and pancreatic ducts of the definitive host, deposit eggs that reach the environment through host feces. After the ingestion by a suitable freshwater snail of the genus Bithynia (WHO, 1995; Hering-Hagenbeck and Schuster, 1996), eggs release miracidia, which undergo three developmental stages (sporocysts, rediae and cercariae). The free-swimming cercariae penetrate into fish of the family Cyprinidae (of the genera Abramis, Alburnus, Aspius, Barbus, Blicca, Carassius, Chondrostoma, Cobitis, Cyprinus, Gobio, Leuciscus, Phoxinus, Polecus, Rutilus, Scardinius and Tinca) (WHO, 1995), encysting as metacercariae mainly in the body muscles. The definitive hosts (fisheating mammals including humans) become infected by ingesting fish harbouring metacercariae. Adult flukes are reported mainly from domestic cat (Hering-Hagenbeck and Schuster, 1996; Oliveira et al., 2005) and fox (Vulpes vulpes) (Schuster et al., 1999). The muskrat (Ondatra zibethicus) was found positive in former USSR (Shuteev, 1977) and Germany (Pauly et al., 2003). The human infection follows the consumption of raw, undercooked, salted, cold smoked or marinated fish (Yossepowitch et al., 2004).

In Europe, O. felineus in humans is endemic in Byelorussia, Russia and Ukraine (Keiser and Utzinger, 2005), with prevalence ranging from 5\% to 40\% (Zavoikin et al., 1989; Nesterenko et al., 1990) and sporadically recorded in Germany, Greece, Poland and Baltic states (Yossepowitch et al., 2004; Armignacco et al., 2008). In Italy, O. felineus was first described at the end of the 19th century (Rivolta, 1884; Perroncito, 1901) from cats and dogs. From then on, this parasite was not reported in animals and humans until recently, with 4 human outbreaks reported from Central Italy (Crotti et al., 2007; Armignacco et al., 2008). Following the outbreak occurred in northern Lazio (Central Italy) in August 2007 (Armignacco et al., 2008), a survey was carried out on the occurrence of $O$. felineus in fishes and snails from two lakes of Central Italy and in mammalian feces collected from their shores, in order to investigate about the diffusion and the natural cycle of this parasite in the area and to evaluate the risk for the consumers.

\section{Materials and methods}

\subsection{Study area}

Bolsena (305 m a.s.l., maximum depth $151 \mathrm{~m}$, mean $81 \mathrm{~m}$ ) and Bracciano ( $160 \mathrm{~m}$ a.s.l., maximum depth $165 \mathrm{~m}$ ) lakes are located in northern Lazio (Central Italy), with a surface of $113 \mathrm{~km}^{2}$ and $56 \mathrm{~km}^{2}$, respectively. Water supply is mainly meteoric; two small rivers drain water from the lakes to the Tyrrhenian Sea north of Rome. In both lakes, the fish species composition is the result of repeated manmade intakes through the years, even with introduction of alien species. Coregonus sp. and Atherina boyeri are the two more important species for the local fishery, with approximately
115 and 50 tons (cumulative for both lakes) caught per year, respectively. Less than 10 tons is the yearly mean catch of tench (Tinca tinca). The stray cat population has been estimated to be $280-360$ individuals around the Bracciano lake and about 1000 around the Bolsena lake.

\subsection{Statistical analysis}

The main aims of the sampling were to evaluate the prevalence of $O$. felineus in the tench, species already known to harbour the parasite since it was the ascertained source of infection for the human outbreaks (Crotti et al., 2007; Armignacco et al., 2008), and to rule out its presence in other fish species, with special reference to Coregonus sp. Therefore, the sample sizes were calculated following two different methods: for tench to determine the prevalence; for other species to detect parasite presence. The target population was assumed as infinite. The sampling criteria used were: for tench, $70 \%$ expected prevalence (Bossù et al., 2008); $10 \%$ accepted error, $95 \% \mathrm{CL}$; for the more frequently fished species, $1 \%$ minimum expected prevalence, $95 \% \mathrm{CL}$; for the other species, $5 \%$ minimum expected prevalence, $95 \% \mathrm{CL}$. According to these criteria, 81 individuals of tench, 298 of Coregonus sp. and 58 of each of the other species had to be tested. A convenience sampling of cat stools around the lakes borders was organised, considering the possibility of the multiple examination of stools from the same individual. Also for snails a convenience sample was analyzed.

In order to compare the risk of infection for intermediate and definitive hosts in the two sampling sites, the odd ratio (OR) was calculated, taking the one for Bolsena lake as baseline risk level. For snails, examined in pools, the "minimum infection rate" was calculated, assuming that in a positive pool only one specimen was infected (conservative hypothesis). For fish, the association between the prevalence and the fish length and weight was tested by $\chi^{2}$-test, dividing the fish into quartiles for both variables.

\subsection{Fish}

Between September 2007 and December 2008, 894 fish belonging to 12 species were collected from the two lakes (Table 1) from fishermen and fish dealers. Fish were transported on ice to the laboratory and stored at $4{ }^{\circ} \mathrm{C}$ until examination. After species identification and length and weight measurements of each specimen (Table 1), the fish were individually tested for the presence of metacercariae. Muscle compression and artificial digestion were used (Thu et al., 2007), the latter allowing the examination of up to $50 \mathrm{~g}$ of fish meat for each digestion. After digestion, metacercariae were singled out and collected from the sediment by a stereomicroscope.

\subsection{Stool}

Eighty-seven fecal samples of 5 putative definitive host species were analyzed: 56 from cats, 13 from dogs, 9 from nutrias (Myocastor coypus), 7 from foxes ( $V$. vulpes) and 2 from rats (Rattus sp.). Fecal samples were collected in strict proximity of the two lakes where fish were sampled, 
Table 1

Species and features of fish from the Bolsena and Bracciano lakes tested for metacercariae.

\begin{tabular}{|c|c|c|c|c|c|c|c|c|c|}
\hline \multirow[t]{2}{*}{ Species } & \multicolumn{3}{|c|}{ Number examined } & \multicolumn{3}{|c|}{ Length $(\mathrm{cm})$} & \multicolumn{3}{|c|}{ Weight (g) } \\
\hline & Bolsena & Bracciano & Total & Mean & Min & Max & Mean & Min & Max \\
\hline Atherina boyeri & 6 & 129 & 135 & 7.6 & 4.6 & 10.0 & 3.2 & 0.7 & 6.7 \\
\hline Carassius carassius & 34 & 5 & 39 & 29.6 & 13.5 & 40.5 & 539.7 & 46.1 & 1283.0 \\
\hline Chondrostoma genei & 18 & 0 & 18 & 24.8 & 21.0 & 34.0 & 187.0 & 110.1 & 398.3 \\
\hline Coregonus sp. & 254 & 13 & 267 & 30.2 & 25.0 & 37.5 & 195.3 & 125.3 & 398.6 \\
\hline Cyprinus carpio & 35 & 6 & 41 & 30.3 & 17.0 & 51.0 & 531.3 & 63.3 & 1299.2 \\
\hline Esox lucius & 15 & 2 & 17 & 34.8 & 30.0 & 48.0 & 340.8 & 182.0 & 817.7 \\
\hline Ictalurus melas & 91 & 2 & 93 & 18.6 & 13.2 & 36.0 & 85.6 & 26.7 & 308.4 \\
\hline Lepomis gibbosus & 46 & 20 & 66 & 10.8 & 4.5 & 15.0 & 38.8 & 1.9 & 81.9 \\
\hline Micropterus salmoides & 24 & 16 & 40 & 18.9 & 12.5 & 29.0 & 113.4 & 19.7 & 331.4 \\
\hline Perca fluviatilis & 19 & 2 & 21 & 26.1 & 14.0 & 97.5 & 73.6 & 17.3 & 144.3 \\
\hline Scardinius erythrophthalmus & 14 & 12 & 26 & 21.3 & 6.0 & 31.0 & 153.7 & 3.5 & 438.9 \\
\hline Tinca tinca & 44 & 87 & 131 & 23.7 & 4.0 & 48.0 & 250.8 & 1.1 & 1300.0 \\
\hline
\end{tabular}

mainly along sandy shores. Stool sample specific identification was confirmed by 165 rDNA sequence analysis using primers previously described (Karlsson and Holmlund, 2007). In order to detect opisthorchiid eggs in stool samples, formalin-ethyl acetate concentration technique was used (Long et al., 1985).

\subsection{Snails}

From June 2008 to July 2009, 4983 specimens of snails of the genus Bithynia were harvested from the Bolsena (351) and the Bracciano (4632) lakes. Sampling consisted in collecting weed from lake bottom; weeds were then placed in plastic bags, kept at $4{ }^{\circ} \mathrm{C}$ until they reached the laboratory, transferred into a white dish, diluted in tap water and searched thoroughly for snails. The snails were identified to genus level and measured. Each snail was then extracted from its shell, pooled according to the site of collection and placed in plastic vials. Each pool consisted in 20 up to 40 specimens. When the snail size was $<1-3 \mathrm{~mm}$, the pooled material included the shells. Pooled samples were then stored at $-20^{\circ} \mathrm{C}$ until DNA extraction.

\subsection{Molecular analysis}

Metacercariae were identified by PCR analysis targeting for all the species of the family Opisthorchiidae (Muller et al., 2007). Eggs from stool samples were also identified by the same protocol. In this case, prior to extract parasite DNA, a clean-up procedure for the purification of eggs from fecal material was performed (Muller et al., 2007). Each snail pool was vigorously triturated using plastic pestles before the DNA extraction for the molecular identification of sporocyst-positive samples.

The total DNA extraction was obtained using QIAamp DNA mini kit (Qiagen) for single metacercariae and sporocysts from snails, whereas the QIAamp DNA stool mini kit (Qiagen) was used to extract DNA from stool samples.

The PCR protocol was as follows: $2 \mu$ l of DNA were transferred in $50 \mu \mathrm{l}$ final volume of an amplification mix containing: EZ buffer $1 \times, \mathrm{Mn}(\mathrm{OAc})_{2} 2.5 \mathrm{mM}$; rTth $5 \mathrm{u}$ (rTth EZ buffer pack, Applied Biosystems); dNTPs $300 \mu \mathrm{M}$ each (GE Healthcare); non-acetylated ultra pure BSA $20 \mathrm{mM}$ (Ambion), primer OP1 and OP2 $300 \mathrm{nM}$ each (Muller et al., 2007). The amplification reaction was performed as follows: $94^{\circ} \mathrm{C} \times 60 \mathrm{~s} ; 40$ cycles $94^{\circ} \mathrm{C} \times 15 \mathrm{~s}, 54^{\circ} \mathrm{C} \times 30 \mathrm{~s}$, $65^{\circ} \mathrm{C} \times 60 \mathrm{~s} ; 65^{\circ} \mathrm{C} \times 5 \mathrm{~min}$. The expected $250 \mathrm{bp}$ amplification product was visualized by the QIAxcel electrophoresis system (Qiagen).

Sequence analysis has been performed on an ABI 310 instrument, using Big Dye terminator chemistry (Applied Biosystems) and the same PCR primers were used for the cycle sequencing reactions. The sequences from both strands have been assembled by SEQMAN software (DNA Star) and then challenged against the GenBank database using the nBLAST tool freely available on NCBI web pages.

\subsection{Detection of snail DNA}

Due to the significant matrix effect as a result of the inhibitory factors present in the mollusc tissues, 6 randomly selected pooled samples of snail were subjected, after DNA extraction, to amplification of a fragment of the cytochrome c oxidase subunit I (COI) gene using the primers COF14 and COR722b (Benke et al., 2009), able to recognize a wide range of metazoan invertebrates. The assay was employed as external amplification control (EAC) to evaluate DNA extraction efficiency. All amplicons were visualized in agarose gel electrophoresis as a single band of about $650 \mathrm{bp}$, as expected.

\section{Results}

The tench was the only species found positive for metacercariae, with an overall prevalence of $88.5 \%$ (116/131). Positive fish originated from both the Bolsena (prevalence 75.0\%) and Bracciano (prevalence 95.4\%) lakes (Table 2), being the lake of provenience an important risk factor $(\mathrm{OR}=7.5)$. The maximum number of metacercariae for each fish exceeded 50/50 g of fillet. After digestion, most of the metacercariae were alive, with the encysted larva showing active movements and in some case about excysting. No infection was detected in 267 tested specimens of Coregonus sp. Sixty (92.3\%) out of 65 metacercariae from tenches collected in both the lakes were identified as $O$. felineus after PCR amplification and sequencing. The sequences (about $200 \mathrm{bp}$ : primer regions at $5^{\prime}$ and $3^{\prime}$ ends have been erased before "blasting") showed $100 \%$ homol- 
Table 2

Prevalence of Opisthorchis felineus in intermediate and definitive hosts from the Bolsena and Bracciano environments.

\begin{tabular}{|c|c|c|c|c|c|c|c|c|c|}
\hline \multirow[t]{2}{*}{ Species } & \multicolumn{3}{|l|}{ Bolsena } & \multicolumn{3}{|l|}{ Bracciano } & \multicolumn{3}{|l|}{ Total } \\
\hline & $\begin{array}{l}\text { Number } \\
\text { examined }\end{array}$ & $\begin{array}{l}\text { Prevalence } \\
(\%)\end{array}$ & $\mathrm{CI}$ & $\begin{array}{l}\text { Number } \\
\text { examined }\end{array}$ & $\begin{array}{l}\text { Prevalence } \\
(\%)\end{array}$ & $\mathrm{CI}$ & $\begin{array}{l}\text { Number } \\
\text { examined }\end{array}$ & $\begin{array}{l}\text { Prevalence } \\
(\%)\end{array}$ & $\mathrm{CI}$ \\
\hline Bithynia sp. & $12^{\mathrm{a}}$ & $0.6^{\mathrm{b}}$ & $0.02-2.2$ & $166^{a}$ & $0.04^{\mathrm{b}}$ & $0.0-0.2$ & $178^{a}$ & $0.08^{\mathrm{b}}$ & $0.02-0.2$ \\
\hline Tinca tinca & 44 & 75.0 & $59.7-86.8$ & 87 & 95.4 & $88.4-98.5$ & 131 & 88.5 & $81.5-93.4$ \\
\hline Cat & 41 & 36.6 & $22.1-53.1$ & 15 & 73.3 & $47.6-89.5$ & 56 & 46.4 & $33.0-60.2$ \\
\hline
\end{tabular}

a Pools.

b Minimum infection rate.

ogy with those of 0 . felineus species. No association was observed between prevalence and fish length $(p=0.24)$ or weight $(p=0.22)$.

Opisthorchiidae eggs identified as belonging to $O$. felineus were found only in cat feces, with an overall prevalence of $46.4 \%$ (36.6\% and $73.3 \%$ in the populations of Bolsena and Bracciano, respectively) (Table 2), resulting in an higher risk of infection in cats around the Bracciano lake $(\mathrm{OR}=4.8)$.

A total of 178 pools of Bithynia (12 from the Bolsena lake and 166 from the Bracciano lake) was analyzed by PCR. $O$. felineus DNA was detected in four pooled samples (2.2\%), two from the Bolsena (13.3\%) and two from the Bracciano (1.2\%) lake. Assuming the presence of one positive snail for each one of the positive pools, the overall minimum infection rate was $0.08 \%, 0.04 \%$ and $0.6 \%$ in Bracciano and Bolsena, respectively (Table 2 ).

\section{Discussion and conclusion}

The present data confirm the endemic presence of $O$. felineus in the study area and allowed to sort out its whole life cycle. Snails of the genus Bithynia, tenches and cats are the intermediate and definitive hosts of the parasite in the two foci of the Bolsena and Bracciano lakes. Values of prevalence were higher than expected both in tench and cat, thus suggesting a widespread and massive circulation of the parasite in the study areas, although its presence was unrecorded until the human outbreak of August 2007 (Armignacco et al., 2008). O. felineus was firstly described in Italy (Rivolta, 1884), however the lack of human cases could have been due to the infrequent consumption of raw fish in Italy, until recently. In fact, raw fish preparations have become popular in Italy only in the last few years. An apposite survey carried out after the 2007 outbreak allowed to highlight that nowadays almost all restaurants close to the two lakes offer raw fish courses in their menu.

Our data permitted to identify the tench as the only dangerous fish for human consumption in the study area, with a prevalence comparable with that observed in Rutilus rutilus and Alburnus alburnus from Germany (HeringHagenbeck and Schuster, 1996). At the beginning of this study, it was considered of relevant importance to define the risk associated to the consumption of Coregonus sp., the most important commercially exploited species in both lakes, often consumed raw marinated. The lack of infection in Coregonus sp. can be explained by the pelagic habits of this species, making unlikely the contact between $O$. felineus cercariae, typical bottom dwellers, and this fish species.
The prevalence of infection in Bithynia snails is low, but comparable with previous data, where prevalence values as low as $0.05-0.07 \%$ were reported (Brockelman et al., 1986). Nevertheless, a low prevalence of Opisthorchiidae in snails, even in presence of high prevalence in fish and in definitive hosts, are rather frequent (Kaewkes, 2003); in fact, a single snail can excrete many cercariae per day along its whole life span, thus determining the infection of a large number of fish.

Both lakes are characterized by sudden variations in water level, possibly causing submersion of feces deposited on shores and thus allowing contamination of water bodies with parasite eggs. The higher prevalence recorded in cats from Bracciano could be due to the sampling, carried out mainly in a site of landing where fishermen use to toilette fish and discharge smaller ones, thus facilitating the cycle, while around the Bolsena lake feces were randomly sampled along shores. However, as a significantly higher prevalence was recorded from this lake also in tench, some environmental/ecological factor could make this site more favourable to parasite life cycle respect to Bolsena.

This parasitosis represents, to our knowledge, a new and only recently recognized public health problem in Italy (Armignacco et al., 2008). At present, after the first alert, several research groups are investigating on this parasite in different areas of the country, to figure out its distribution and the eventually associated risk. In the immediate future, further researches will be aimed to test more specimens of some cyprinids species (Barbus plebejus, Carassius carassius, Cyprinus carpio, Leuciscus cephalus, etc.), in order to check their safety for human consumption. Until now, these species have had a low commercial value and were only sporadically caught and used for human consumption in Italy; in fact, in the last years their use increased because of the development of a multiethnic society, particularly with the arrival of people from Asiatic and eastern European countries. Besides, globalisation is causing a shift in feeding habits even among Italians, with a growing number of people usually eating raw or undercooked fish.

\section{Acknowledgements}

Research funded by the Italian Ministry for Health. Authors are grateful to Laura Mancini for help and training in snail identification.

\section{References}

Armignacco, O., Caterini, L., Marucci, G., Ferri, F., Bernardini, G., Natalini Raponi, G., Ludovisi, A., Bossù, T., Gomez Morales, M.A., Pozio, E., 2008. 
Human illnesses caused by Opisthorchis felineus flukes, Italy. Emerg. Infect. Dis. 14, 1902-1905.

Benke, M., Brändle, M., Albrecht, C., Wilke, T., 2009. Pleistocene phylogeography and phylogenetic concordance in cold-adapted spring snails (Bythinella spp.). Mol. Ecol. 18, 890-903.

Bossù, T. Scaramozzino, P., Martini, E., Lorenzetti, R., Brozzi, A, De Liberato, C., 2008. Survey on the presence of Opisthorchis felineus (Platyhelminthes, Digenea) metacercariae in fish from Bolsena and Bracciano lakes (Central Italy). Parassitologia 50, 152.

Brockelman, W.Y., Upatham, E.S., Viyanant, V., Ardsungnoen, S., Chantanawat, R., 1986. Field studies on the transmission of the human liver fluke, Opisthorchis viverrini, in northeast Thailand: population changes of the snail intermediate host. Int. J. Parasitol. 16, 452-545.

Crotti, D., D'Annibale, M.L., Crotti, S., 2007. Opisthorchiasi autoctona al Lago Trasimeno (Perugia): descrizione di due episodi epidemici da Opisthorchis felineus e problematiche diagnostiche differenziali. Microbiol. Med. 22, 36-41.

Hering-Hagenbeck, S., Schuster, R., 1996. A focus of opisthorchiidosis in Germany. Appl. Parasitol. 37, 260-265.

Kaewkes, S., 2003. Taxonomy and biology of liver flukes. Acta Trop. 88, 177-186.

Karlsson, A.O., Holmlund, G., 2007. Identification of mammal species using species-specific DNA pyrosequencing. Forensic Sci. Int. 173 (1), 16-20.

Keiser, J., Utzinger, J., 2005. Emerging foodborne trematodiasis. Emerg. Infect. Dis. 11, 1507-1514.

Long, E.G., Tsin, A.T., Robinson, B.A., 1985. Comparison of the FeKal CON-Trate System with the formalin-ethyl acetate technique for the detection of intestinal parasites. J. Clin. Microbiol. 22 (2), 210-211.

Marcos, L.A., Terashima, A., Gotuzzo, E., 2008. Update on hepatobiliary flukes: fascioliasis, opisthorchiasis and clonorchiasis. Curr. Opin. Infect. Dis. 21, 523-530.

Muller, B., Schmidt, J., Mehlhorn, H., 2007. PCR diagnosis of infections with different species of Opisthorchiidae using a rapid clean-up procedure for stool samples and specific primers. Parasitol. Res. 100, 905909.
Nesterenko, N.P., Morozova, I.A., Kondrat'eva, L.P., Donets, N.P., 1990. Opisthorchiasis in Chernigov Province (the situation and control and prevention measures). Med. Parazitol. (Mosk) 4, 21-22.

Oliveira, P., Pires, M.A., Rodrigues, P., Ginja, M., Pires, M.J., Pires, I., Cardoso, L., Antunes, L., Rodrigues, M., 2005. Opisthorchis felineus in cat: case report. Arq. Bras. Med. Vet. Zootec. 57, 556-558.

Pauly, A., Schuster, R., Steuber, S., 2003. Molecular characterization and differentiation of opisthorchiid trematodes of the species Opisthorchis felineus (Rivolta, 1884) and Metorchis bilis (Braun, 1790) using polymerase chain reaction. Parasitol. Res. 90, 409-414.

Perroncito, E., 1901. I parassiti dell'uomo e degli animali utili e le più comuni malattie da essi prodotte. Vallardi Editore, Milan, $400 \mathrm{pp}$.

Rivolta, S., 1884. Sopra una specie di distoma nel gatto e nel cane. G. Anat. Fisiol. Patol. Anim. 16, 20-28.

Schuster, R., 2010. Opisthorchiidosis-a review. Infect. Disord. Drug Targets 10 (5), 402-415.

Schuster, R., Bonin, J., Staubach, C., Heidrich, R., 1999. Liver fluke (Opisthorchiidae) findings in red foxes (Vulpes vulpes) in the eastern part of the Federal State Brandenburg, Germany. A contribution to the epidemiology of opisthorchiidosis. Parasitol. Res. 85, 142-146.

Shuteev, M.M., 1977. Parasitic fauna of the muskrat from the upper Ob' pine forest. Parazitologiia 11, 538-540.

Sripa, B., 2003. Pathobiology of opisthorchiasis: and update. Acta Trop. 88, 209-220.

Thu, N.D., Dalsgaard, A., Loan, L.T.T., Murrell, K.D., 2007. Survey for zoonotic liver and intestinal trematod metacercariae in cultured and wild fish in An Giang Province, Vietnam. Korean J. Parasitol. 45, 45-54.

World Health Organization (WHO), 1995. Control of foodborne trematode infections. WHO Technol. Rep. Ser. 849, 1-157.

Yossepowitch, O., Gotesman, T., Assous, M., Marva, E., Zimlichman, R., Dan, M., 2004. Opisthorchiasis from imported raw fishes. Emerg. Infect. Dis. 10, 2122-2126.

Zavoikin, V.D., Beer, S.A., Pliushcheva, G.L., Sholokhova, S.E., Nikiforova, T.F., 1989. Opisthorchiasis at left Dnieper watersheds. Med. Parazitol. (Mosk) 2, 9-14. 